\title{
Brief Analysis of Talents Reserve for Dalian Japanese Bookkeeping
}

\author{
Xue-chao Xu \\ Dalian Neusoft University of information, Japanese Department, Dalian, Liaoning, China
}

\begin{abstract}
With the influence of economic globalization, we demand many talented people as a huge adjustment lever on education. Taking Dalian soft park for example, It has carried on the investigation and Analysis on the demand of Japanese enterprises to Japanese bookkeeping talents. It has great importance for the professional structure of higher school in setting. The author thinks that the traditional single mode of training only has the knowledge and skills of the Japanese talent so far can not meet the needs of the situation, requirements of colleges. Universities should be the regional economic and social development, establish and perfect the talent training mode, clear training objectives, the reform of teaching methods, optimize the teaching content. This study is designed to let more Japanese professional colleges and universities understand Japan's bookkeeping. It cultivates more qualified Japanese bookkeeping talents for the period of simple learning. Japanese students learning approach in many aspects such as the choice of the way of future careers with more skills, providing a reference to solve problems of Japanese professional graduates.
\end{abstract}

Keywords - Japanese bookkeeping, bookkeeping teaching, social demands

\section{浅析大连日式簿记人才的社会储备情况}

\author{
徐学超 \\ 大连东软信息学院日语系, 大连, 辽宁, 中国
}

摘 要 伴随着世界经济的全球化, 大量日本企业进驻中国, 对日语人才需求提出了新的要求。本文以大连市软件园为调研对象, 就日企对日式簿记人才的需求状况进行了调查和分析。通过调研分析得知, 传统的单一培养模式和只具备日语知识和技能的人才已远 远不能适应新形势的需要, 高校应从区域经济社会发展的需要出发,建立和完善人才培养模式, 明确培养目标, 改革教学方法,优化教学 资源和内容。新的人才需求是大学专业教育的巨大调节杜杆, 对高等学校专业结构设置起着重要的作用。通过本研究, 旨在让更多的 日语专业院校了解日本的簿记在中国的发展, 培养更多合格的日式簿记人才, 为日语专业学生提供多方面的学习途径, 进而在选择今 后的职涯之路上拥有更多的技能, 为解决日语专业毕业生出路问题提供参考。

关键词 日式簿记, 簿记教育, 社会储备

\section{1. 何为“簿记”}

“簿记”系由英文 book-keeping 翻译而来。Book 意为帐 册或帐簿, Keeping 意为保存、保留、保密等, book-keeping 既是在一种登记簿或日记册上登记帐目的记录实践活动的 意思。简言之, “簿记” 是一种记账方式, 主要是公司在经 营中的资产、负债、纯资产的管理以及公司收益和和各种 费用的记录。

簿记考试有很多种, 目前在中国只可以参加全经日式 簿记能力检定考试。该考试由日本前首相麻生太郎为会长 的日本全国经理教育协会主办, 以日本文部省为其后援机
构，于 1956 年首度举行，至今已有 50 余年的历史。 1983 年 8 月得到了日本国家税务总局的认可, 其上级合格者可 获得日本注册税务师考试的资格。本资格证书在中国是唯 一一个除了语言资格以外可以评价自身职场价值的日本专 业资格证书。有相当于 N2 日语水平者即可学习 3 级、 2 级考试, 有相当于 $\mathrm{N} 1$ 日语水平者可学习 1 级考试。

在日本, 每年都有 100 多万人参加簿记考试。人气居 高不下的原因是：具备簿记相关资格是日本企业录用财务 人员的应聘条件之一; 日本企业大都实行事业部, 每个事 业部都独立核算, 簿记知识是必备知识; 日本劳动省在制 定“商务经验”制度时，将簿记教学计划作为其组成部分。 
在日本, 很多资格考试中也设置簿记考试的内容, 如建设 业财务事务士、计算机财务会计主任、银行业务检定、证 券分析员、税务会计能力检定、国家税务公务员、国税专 门官、财务搜查官等资格考试, 都需要考簿记知识。特别 是公认会计士、税理士、中小企业诊断士、房地产鉴定士 资格考试中，簿记知识的考试份量更显重要。

在中国, 簿记资格作为衡量企业和个人会计知识的基 本条件, 已经被越来越多的日企列入了招贤纳士的的重要 标准之一。因此, 国内的日语专业学生如若取得日式簿记 相关资格, 对于未来的日企求职、个人职业发展等都有重 要的参考和实用价值, 将来在日本就职时也必然会增加个 人砝码。

\section{2. 大连日式簿记人才的调研分析}

笔者从 2014 年年初开始, 通过问卷调查, 实地走 访, 近距离访谈等方式, 对大连软件园周边企业进行了相 关调研。调研结果总结如下。

\section{1 进驻大连的大型企业逐渐增多, 对日贸易所占比重很} 高。

通过对大连软件园周边企业的实地走访发现, 近几年 进驻大连的大型企业, 尤其是以软件开发为主的大型公司 和企业逐渐增多, 软件园区内如 IBM、HP、DELL、 Genpact 等跨国 IT 企业就有 23 家, 另外, 如 Neusoft、 Pactera 等国内许多企业对日贸易也在不断增加, 尤其是大 连软件和服务外包产业发展迅速。2012 年, 大连市软件业 销售收入突破千亿大关, 出口 35 亿美元, 大连软件园、 东软软件园、腾飞软件园等软件园区迅速崛起, 吸引惠 普、IBM、戴尔等 70 多家世界 500 强企业落户, 全市软件 企业达到 1475 家，软件服务外包走在全国前列。

表 1 大连软件园的主要企业分布

\begin{tabular}{|c|l|}
\hline \multicolumn{2}{|c|}{ 大连软件园地区包含对日业务的大型企业 } \\
\hline & IBM、HP、DELL、Genpact、Accenture、SAP、 \\
欧美和日本 & Oracle、Symantec、Convergys、Ericsson、NOKIA、 \\
企业 & BritishTelecom、NCR、AIG、ASICS、Fidelity、 \\
& FLE Group、Cisco Systems、Ernst \& Young、CITI、 \\
& Rockwell automation、AVAYA、SDK。 \\
\hline 中资企业 & $\begin{array}{l}\text { Neusoft、Pactera (文思海辉)、DHC (大连华信)、 } \\
\text { 等 1000 家以上。 }\end{array}$ \\
\hline
\end{tabular}

\section{2 企业对于日语人才需求发生新变化。}

笔者通过对日企招聘管理相关部门的走访获知, 对于 日语专业毕业生的职业素养要求, 除了日语的沟通能力, 必要的商务礼仪常识之外, 实用性强的相关技能, 如: 计 算机技能, 书写邮件, 商务信函的技能, 日式簿记技能等 都是被企业看重的重要用人标准。尤其是随着对日 BPO业 务的人才需求量不断上升, 以往的以日文录入为主的低端 BPO 业务量将大幅度减少, 取而代之的是具有一定财务专 业技能同时具备良好的日语能力，能从事中高端财务 BPO 业务的人才需求量将大幅度增加。因此, 日式簿记技能显 得十分必要。可以说, 以往只会说日语的传统单一人才已 经远远不能满足用人单位的需求了。

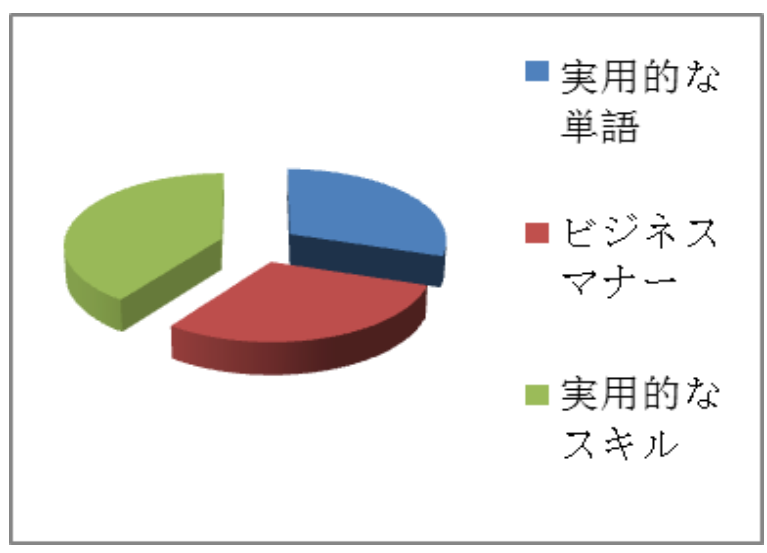

图 1 日企认为毕业生应具备的能力

2.3 日式簿记人才的储备量明显不足。

大连市的日式簿记人才在数量上严重不足, 不能满足 日益增长的市场需求。通过调研发现, 大连地区每年参加 日式簿记考试的人数并不多。就合格率而言, 三级合格率 较高, 而 2 级, 1 级的合格率相对较低, 因此, 日式簿记 人才培养的质量也亟待提高。究其原因, 笔者认为主要在 于高校日语专业对于日式簿记的重视程度和推广程度。

表 2 大连地区日式簿记的报考与合格情况

\begin{tabular}{|c|c|c|c|c|}
\hline \multicolumn{5}{|c|}{ 大连地区 173-176 回日式簿记的报考与合格情况 } \\
\hline 级别 & 科目 & 报考人数 & 合格人数 & 合格率 \\
\hline 1 级 & 会计 & 23 & 11 & $48 \%$ \\
\hline & 工业 & 14 & 13 & $93 \%$ \\
\hline 2 级 & & 184 & 143 & $78 \%$ \\
\hline 3 级 & & 609 & 554 & $91 \%$ \\
\hline
\end{tabular}


2.4 日语专业本科毕业生的择业预期与用人单位的实际 需求存在差异。

在调研过程中笔者发现, 很多日语专业毕业生认为目 前就职的公司, 从事的工作与自己的想象相差甚远, 入职 前对心仪的企业及工作想象同现实不能很好的吻合。如图 4 所示, 想要从事使用日语相关工作学生占 $90 \%$, 而实际 从事了使用日语相关工作的学生只占 $30 \%$, 从事了 BPO 以外的相关工作的学生占 $10 \%$ 。可见, 理想与现实有很大 差距。究其主要原因, 笔者认为, 一方面由于大学生在目 标和角色意识上定位模糊, 即不知道自己适合做什么, 也 没有明确的求职目标。二是毕业生缺乏竞争意识, 没有和 他人竞争岗位的勇气。三是毕业生缺乏获得心仪的工作的 能力, 就日语专业而言, 除了日语之外, 没有其他就业砝 码的毕业生不在少数。目前大连市的日语专业人才较国内 其他城市明显占据优势, 但主要从事 BPO 行业相关工作, 中高端行业人才明显不足。

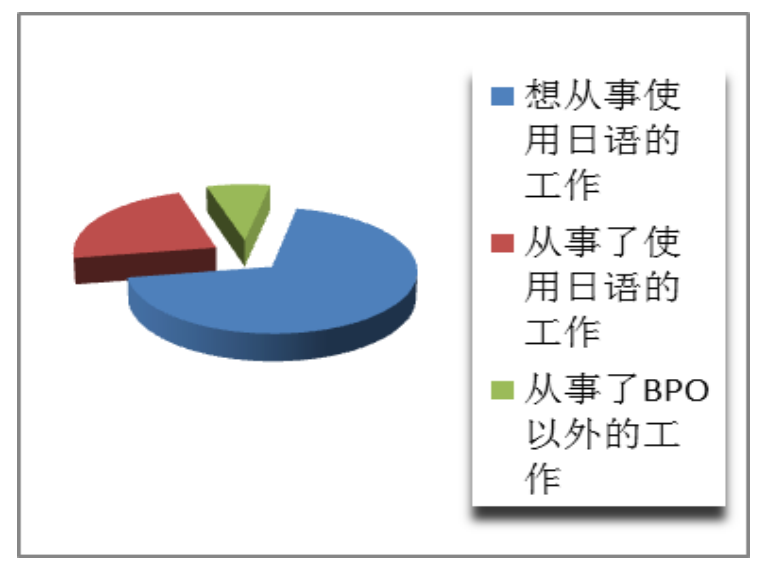

图 2 日语专业毕业生的择业预期和实际情况

\section{3. 结论}

基于调研的相关数据分析可知, 大连市的日式簿记人 才在数量上严重不足, 不能满足日益增长的市场需求。由 于职业技能不足, 很多地方高校的日语毕业生面临着“毕 业即失业”的命运。一方面是企业界招不上急需的高技能 日语人才, 另一方面却是大量高校日语毕业生找工作难, 企业与高校间的产教融合度较低。究其原因和解决方案, 笔者总结为以下几方面。

\section{1 用人单位的实际人才需求与高校日语毕业人才的有效 供给相脱节。}

发达国家的高等院校都高度重视产教融合、校企合 作, 高度重视大学生的创新创业能力和技术技能培养, 毕
业生很快就能够在各行各业创造新的国民财富, 而我国教 育系统很大程度上依然未能摆脱“应试教育”的羁绊。就日 语专业而言, 很多毕业生在毕业时, 大部分都拥有日语国 际能力 1 级合格证书, 日语专业 8 级合格证书, 但是几纸 证书却不代表学生的真正动手能力, 更不能满足用人单位 的用人需求。

3.2 高校日语专业课程设置缺乏前瞻性, 与人才需求脱节。

我国金融财务 BPO 行业刚起步, 高校尚未全面进行市 场调研, 在人才培养方案中缺乏涉及针对金融财务 $\mathrm{BPO}$ 行 业人才培养模式以及技能培训课程, 诸如日式簿记等专业 技能的培养方式, 课程设置与人才需求相脱节极为明显。 就大连地区而言, 开设日式簿记的大学目前只有大连外国 语大学和大连东软信息学院两所大学, 更多的高校还在等 待和观望中徘徊不前。

笔者认为, 用人单位可以通过提前安排有意向的日语 应届毕业生到本单位实习等方式, 将接受毕业生实习作为 一种社会职责和义务, 通过实习传授给学生实践知识和能 力, 并对其在实习阶段暴露出来的问题进行分析并反馈给 高校, 帮助高校发现培养学生过程中存在的不足和问题。 而高校方不但要优化课程设置, 提高教学质量, 加强实践 教学, 提高学生应用能力之外, 还应积极加强校企合作, 为学生开拓广泛的实习和实践基地, 真正意义上实现学以 致用, 活学活用。

\section{3 有梯度的提升教师的跨专业指导能力势在必行。}

日语专业教师队伍素质直接决定了日语专业的教学实 力和发展潜力。高校日语专业应该拓展教师进入日本企 业, 了解 BPO财务流程的渠道, 落实教师密切联系企业的 责任。除了 BPO行业所需求的簿记知识, 如何考取翻译资 格, 日本导游资格等, 日语专业教师们的跨专业指导能力 和实践能力也需要在繁重的科研能力下予以重视和鼓励, 并纳入相关的科研或教研能力考核范围之内。不仅仅是日 语专业, 当前, 地方高校的大部分教师缺少在企业锻炼和 从业的经历, “双师型”教师队伍的建设势在必行。

综上所述, 如何采取积极有效的措施, 提高日语专业 毕业生的综合素质, 尤其是实务工作能力, 积极应对新的 行业需求下日语专业毕业生的就业困境, 是高校人才培养 和就业工作迫切需要解决的现实问题。

作为企业, 可以通过和高校签订订单式培养协议、联 合开展科技攻关、建立毕业生实习见习就业基地等方式, 解决相关专业毕业生的就业问题。 
作为高校, 要适应日语人才需求变化, 持续优化日语 专业结构, 坚持产教深度融合、校企深度合作, 保障毕业 生能力与岗位实际要求无缝衔接。笔者建议将日本簿记教 育加入日语专业的人才培养方案中, 掌握企业人才需求动 态，培养企业所需人才。

作为日语专业的学生, 要知道日语仅仅是一种沟通的 工具, 并不是一种生存技能。要紧跟日语行业需求, 充分 了解并研究诸如日式簿记人才在日企中的需求和优势, 用 发展的眼光有目的有计划的去学习, 既有扎实, 系统的日 语专业知识, 又钻研一门行业技能, 真正地做到学以致 用, 活学活用。

\section{参考文献(References)}

[1] ChengLing,employment survey and analysis of Japanese langua ge major graduates. Joumal of Changchun University of Science and Technobgy (Higher Education Edition), Qctober2009.

[2] Bu Xian-hua, You Shu-hui, Liu Jian-qun, Zhang Yan-mei, Zhang Hui-min, On development of compound Japanese professional talents from Japanese teaching of IT , Journal of Changchun University, September2006. 